\title{
Intermittent vs continuous stimulation in the development of kinesthetic spatial aftereffects
}

S. H. LOVIBOND AND D. MENICOL

UNIVERSITY OF ADELAIDE

The effect on the KSAE of intermittent versus continuous stimulation from a wooden block between thumb and finger was studied by the method of magnitude estimation. Two groups rubbed the inducing block continuously for $2 \mathrm{~min}$, one actively and one passively. A third group felt the block for $3 \mathrm{sec}$ in each $10 \mathrm{sec}$, and a control group had no contact with the inducing block. The control group showed significant pseudo-KSAE. Significant KSAE in comparison with the control group was observed in the intermittent stimulation group and the passive, continuous stimulation group. The finding of greatest KSAE in the intermittent stimulation group was interpreted as evidence against response decrement theories of KSAE.

Following the original work of Gibson (1933), the phenomenon of kinesthetic spatial aftereffect (KSAE) has been extensively investigated. Nevertheless, a generally acceptable account of the mechanism of the phenomenon has failed to emerge. The most influential theory has been that of Kohler and Wallach (1944), who account for the KSAE in terms of a process of increased cortical resistance or "satiation," consequent upon prolonged stimulation. Other "response decrement" theories of KSAE have been proposed by Eysenck (1955) and Duncan (1956), who have explained the phenomenon in terms of Hull's concept of reactive inhibition.

As an alternative to the response decrement hypothesis, several theorists have suggested that the essential mechanism underlying the KSAE is the establishment of some form of internalized representation of spatial extent, against which subsequent kinesthetic input is judged. Broadbent (1961) e.g., has described the process whereby $S$ "'builds up a scale of judgment," and Costello (1962) has referred to S's "frame of reference." Frame of reference accounts either explicitly or implicitly relate the KSAE to the phenomena of the contrast illusions (Bzhalava, 1961). The available evidence does not permit an evaluation of the alternative theories of KSAE. Most studies have used the tapered block method of Klein and Krech (1952), and Broadbent has demonstrated the possibility of artifact in measures derived from this method. One of the purposes of the present study was to develop an unbiased and sensitive method of measuring the KSAE. The method adopted was the method of magnitude estimation reported by Stevens (1956). This method has been applied with considerable success to magnitude judgments of loud- ness of sounds, shock intensity, and a variety of other perceptual continua. Since Stevens and Stone (1959) have reported magnitude judgments of the thickness of blocks of wood, the technique would seem to be applicable to the study of KSAEs.

A second purpose of the investigation was to study the effect on the KSAE of intermittent vs continuous stimulation during the inducing phase. Response decrement theory clearly predicts that continuous stimulation will produce greater KSAEs than intermittent stimulation, since continuous stimulation from the stimulus block is necessary if maximum satiation is to be attained. Evidence has been produced to show that continuous fixation of the stimulus figure is needed to produce maximal visual aftereffects (Gibson, 1933; Summerfield \& Miller, 1955), and most investigators appear to have assumed that continuous rubbing over relatively long periods is necessary to produce maximal KSAEs. For example, Day and Singer (1964) describe the KSAE as a phenomenon "which is dependent on prolonged kinesthetic stimulation." From the point of view of frame of reference theory, however, intermittent contact with the stimulus block should be sufficient to establish the required internal representation of spatial extent.

\section{METHOD}

\section{Subjects}

The Ss were 80 male students from an introductory psychology class in the University of Adelaide.

\section{Apparatus}

The apparatus consisted of nine blocks of smooth hardwood 12 in. long and 4 in. high. There was one standard block, 1-1/2 in. wide, one stimulus block, $2-1 / 2$ in. wide, and seven test blocks, with widths ranging from $1-1 / 4$ in. to $1-5 / 8$ in. in $1 / 16$ in. increments. The stimulus block, which was placed beneath a wooden arm-rest, could remain stationary or could be moved backwards and forwards between S's thumb and finger by $\mathrm{E}$.

The S sat on a chair, and the standard block rested on a surface alongside $S$, just below the level of the chair. On the other side of $S$ was the arm-rest described above, beneath which could be introduced the stimulus block or any of the seven test blocks.

\section{Procedure}

The Ss were allocated at random to one of four 
groups: (1) Control Group (C); (2) Active Rub Group (A/R); (3) Passive Rub Group (P/R); (4) Feel Group (F).

Prestimulation phase. In the prestimulation phase, which was the same for all four groups, $\mathrm{S}$ was seated on the chair, blindfolded, and required to judge the thickness of the seven test blocks with the nonpreferred hand. The procedure followed Stevens' method of magnitude estimation. The $S$ was given the $1-1 / 2$ in. thick standard block in the preferred hand, and was told that its thickness had been given the value 10 . The seven test blocks were then presented in random order, and $S$ assigned values to them in terms of their thickness relative to that of the standard.

Stimulation phase. The stimulation phase followed immediately, and lasted for 2 min. During this time $S$ could hear a metronome set at the rate of 105 beats/ min. The $\mathrm{C}$ group sat without talking or moving for the $2 \mathrm{~min}$ period. In the $\mathrm{A} / \mathrm{R}$ group treatment, $\mathrm{S}$ was given the $1 / 2$ in. thick stimulus block in the nonpreferred hand and was told to rub it in time to the metronome. In the case of the $P / R$ group, $S$ was given the $2-1 / 2$ in. thick stimulus block in the nonpreferred hand. The $S$ was instructed to place his arm on the rest while $E$ rubbed the block backwards and forwards between S's fingers in time to the metronome. The Ss in the $\mathbf{F}$ group placed the nonpreferred arm on the rest while $\mathrm{E}$ introduced the $2-1 / 2$ in. thick stimulus block underneath. On the instruction from E, S dropped his hand down on to the stimulus block, and felt it for a duration of $3 \mathrm{sec}$. On the instruction "Stop," $\mathrm{s}$ took his hand off the block and rested for $7 \mathrm{sec}$ with his arm still on the rest. This procedure was repeated throughout the $2 \mathrm{~min}$ period, $\mathrm{S}$ alternately feeling for $3 \mathrm{sec}$, and then resting for the next $7 \mathrm{sec}$.

Test phase. The test phase followed immediately after the stimulation phase and was the same for all four groups. The $2-1 / 2$ in. thick stimulus block was removed, and $S$ was given the $1-1 / 2$ in. thick standard (value 10) in the preferred hand. A 1-1/2 in. test block was presented twice to the nonpreferred hand, and $S$ was required to make two judgments of its thickness in the same manner as in the prestimulation phase.

\section{RESULTS}

To check the reliability of the method of measurement, the seven subjective judgments of width of the test blocks made by each of the $80 \mathrm{Ss}$ in the prestimulation phase were correlated with the actual width of the blocks, using the Pearson product-moment correlation coefficient. Although Stevens and Stone (1959) have shown that apparent thickness grows as the 1.33 power of stimulus magnitude, in the present experiment only a very narrow range of the thickness continuum was used, and the departure from linearity was minimal. The 80 coefficients were transformed into Fisher's z scores, vhich were averaged and reconverted into $r$ coeffijients to give the mean correlation between subjective judgment :nd actual width for each treatment group of $20 \mathrm{Ss}$, and also a grand mean for the total sample of $80 \mathrm{Ss}$. The coefficients ranged from 0.88 to 0.90 over the four groups, with an average correlation of 0.89 .

For each $\mathrm{S}$, the amount of aftereffect due to contact with the $2-1 / 2$ in. stimulus block was determined as follows: (a) The method of least squares was employed to calculate the regression of subjective judgment on actual width, the size of a unit of the subjective scale in inches, and the prestimulation subjective scale value for the $1-1 / 2$ in. (i.e., standard) block. For a perfect match this last value was 10 . (b) The poststimulation subjective value of the $1-1 / 2$ in. standard block was obtained by averaging the poststimulation judgments. (c) The size of the KSAE, in subjective scale units, was determined by subtracting the calculated prestimulation judgment of the same standard. This value was then converted to inches by multiplying it by the S's subjective scale unit size as determined in (a) above. The score thus obtained was used in all subsequent comparisons. The greater this score, the greater the KSAE, i.e., the greater the illusory sensation of shrinkage of the standard. Table 1 shows the mean KSAE and variance for each of the four treatment groups.

Since Hartley's Maximum F Ratio test of homogeneity of variance failed to reach significance, an analysis of variance was carried out on the KSAE scores. The $F$ test revealed a significant difference between the treatment group means $(F=3.03, d f=3 / 76, p<.05)$. Thirteen of the 20 control Ss obtained positive KSAE scores, and a $t$ test showed this tendency towards pseudo-KSAE in the control group to be significant $(t=2.83, \mathrm{df}=19, \mathrm{p}<.02)$. The $\mathrm{F}$ group showed significantly greater KSAE than the $C$ group $(t=2.91$, $\mathrm{df}=38, \mathrm{p}<.002$; one-tail test). The $\mathrm{P} / \mathrm{R}$ group also showed significant KSAE in comparison with the control group $(t=1.99, d f=38, p<.02$, one-tail test $)$, but none of the remaining comparisons was significant.

\section{DISCUSSION}

It would appear that the use of Stevens' method of subjective scales of magnitude resulted in a relatively sensitive, unbiased estimate of the KSAE. The highly significant correlations between subjective judgment of width and actual width, attest to the precision of the technique. The significant trend towards pseudo-KSAE in the control group suggests that Ss' judgments are susceptible to systematic changes over time, independent of any treatment effects.

Table 1. Mean KSAE shown by each of the four treatment groups, and variances within each group

\begin{tabular}{cccc} 
Treatment Group & Mean KSAE (in) & Voriance & N \\
\hline$C$ & +0.060 & 0.009 & 20 \\
A $R$ & +0.096 & 0.012 & 20 \\
$P / R$ & +0.119 & 0.009 & 20 \\
$H$ & +0.146 & 0.005 & 20 \\
\hline
\end{tabular}


The finding of greatest KSAE in the F group supports frame of reference theory and directly contradicts the theory that satiation is the only source of KSAE. This finding is all the more striking when it is noted that the total amount of time spent in contact with the stimulus block by the F group Ss was only $36 \mathrm{sec}$, compared with $120 \mathrm{sec}$ for the $A / R$ and $P / R$ Ss. The results cast serious doubt on the prediction from satiation theory that size of KSAE is a simple function of time of contact with the stimulus block.

Finally, the results offer no firm support for the conclusion of Bakan and Weiler (1963) that passive movement results in greater KSAE than active movement.

\section{References}

Bakan, P., \& Weiler, E. Kinesthetic after-effect and mode of exposure to the inspection stimulus. J. exp. Psychol., 1963, 65, 319-320.

Broadbent, D. E. Psychophysical methods and individual differences in the kinesthetic figural after-effect. Brit. J. Psychol., $1961,52,97-104$.
Bzhalava, I. T. The nature of the contrast illusion. In N. O'Connor (Ed.), Recent Soviet psychology. London: Pergamon, 1961. Pp. 290-303.

Costello, C. G. The effects of meprobamate on kinesthetic figural after-effects. Brit. J. Psychol., 1962, 53, 17-26.

Duncan, $\mathbf{C}$. $P$. On the similarity between reactive inhibition and neural satiation. Amer. J. Psychol., 1956, 69, 227-235.

Day, R. H., \& Singer, G. The relationship between the kinesthetic spatial aftereffect and variations in muscular involvement during stimulation. Aust. J. Psychol., 1964, 16, 200-208.

Eysenck, H. J. Cortical inhibition, figural aftereffects and the theory of personality. J. abnorm. soc. Psychol., 1955, 51, 94-106.

Gibson, J. J. Adaptation with negative after-effect. Psychol. Rev., $1933,44,222-244$

Klein, G. S., \& Krech, D. Cortical conductivity in the brain injured. J. Pers., 1952, 21, 118-148.

Kohler, W., \& Wallach, H. Figural after-effects: an investigation of visual processes. Proc. Amer. Phil. Soc., 1944, 88, 269-357.

Stevens, S. S. The direct estimation of sensory magnitudes-loudness. Amer. J. Psychol, 1956, 69, 1-25.

Stevens, S. S., \& Stone, G. Finger span: ratio scale, category scale and JND scale. J. exp. Psychol., 1959, 57, 91-95.

Summerfield, A., \& Miller, K. M. Visual illusion and figural aftereffect with and without fixation. Quart. J. exp. Psychol, 1955, $7,149-158$.

(Accepted for publication November 4, 1967.) 